\title{
|||||||||||||||||||||||||||||||||||||||||||||||||||||||||||||||||||.
}

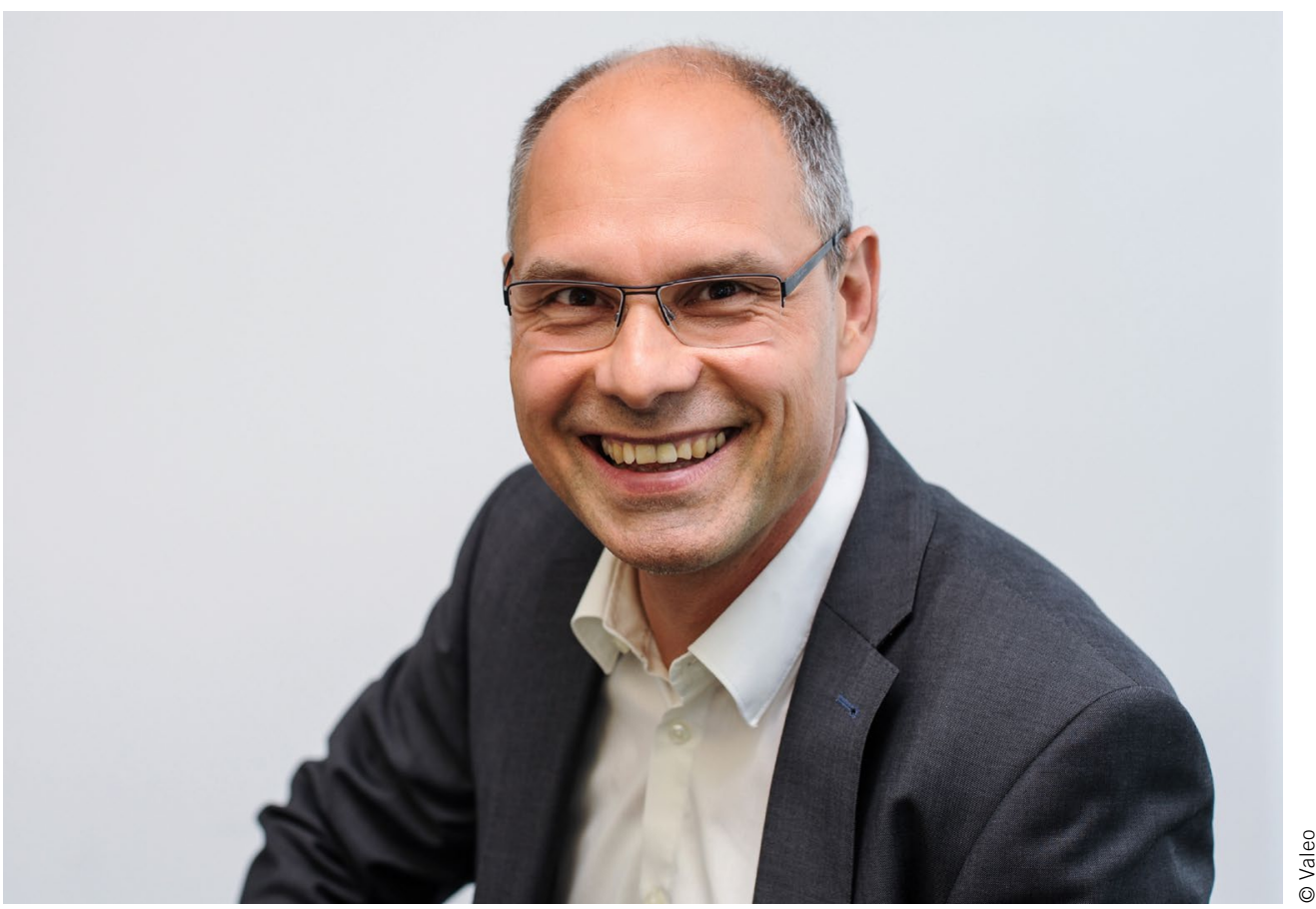

Dipl.-Ing. (BA) Joachim Mathes Chief Technology Officer von Valeo Comfort \& Driving Assistance Systems, ATZ-Beirat

\section{Schöner Wohnen auf vier Rädern}

Früher galt das fahrerorientierte Cockpit als erstrebenswertes Ideal, der Fahrer war das Maß aller Dinge. Heute befindet sich der Innenraum im Wandel zur Lounge für alle Insassen. Die Fahraufgabe tritt in den Hintergrund, individueller Komfort und Wohlfühlatmosphäre für alle Sitzreihen gewinnen an Bedeutung. Das Auto wird den gewachsenen Ansprüchen gerecht, indem es die Insassen erkennt, Stimmung und Gesundheitszustand analysiert und deren unterschiedliche Bedürfnisse und Vorlieben erlernt. Mittlerweile ist die Gestaltung des Innenraums und die „digitale Kontinuität“ - also die durchgängige Vernetzung - eines der wichtigsten Kaufkriterien, vor allem auch in China. Wer aber kümmert sich bei all diesen Ablenkungen noch um den Verkehr?

Aktuell liegt ein Schwerpunkt der Automatisierung auf Unfallvermeidung und Assistenz. Bereits bei der Teilautomatisierung kann der Fahrer zumindest zeitweise seine Aufmerksamkeit anderen Tätigkeiten widmen. Die ersten Serienfahrzeuge fahren in Japan bereits nach SAE-Level 3, weitere Automobilhersteller folgen in den nächsten zwölf Monaten.

Das Interieur der Fahrzeuge passt sich dem Bedarf nach geeigneten Projektionsflächen an. Dafür bietet sich einerseits der Bereich unterhalb der Windschutzscheibe an, andererseits wird die Scheibe selbst zum Display. Hier können reale und virtuelle Welt überlagert werden. Die Herausforderung für die Entwickler liegt dabei darin, Information situationsabhängig nur sichtbar zu machen, wann und wo sie sinnvoll ist.
Ähnlich verändern sich auch die anderen Oberflächen im Pkw. Einerseits gibt es einen starken Wunsch nach natürlichen Materialien als sichtbaren Ausdruck von Nachhaltigkeit und dem Wunsch nach Geborgenheit. Andererseits bekommen diese Oberflächen unterschiedlichste Funktionen, sei es die Interaktion durch Berührungen und Gesten oder eine Flächenheizung. Alle diese Funktionen werden weitestgehend unsichtbar bleiben, nichts soll die schlichte Ästhetik stören.

In mancherlei Hinsicht sind die Innenräume moderner Autos sogar schon komfortabler und intelligenter als viele Wohnungen. Von daher ist der Gedanke, das Auto zum Wohnraum auf vier Rädern zu machen so konsequent wie radikal. Auf der Automesse in Schanghai 2021 war auf dem Stand von Xiaopeng die neue Limousine P5 als mobiles Zuhause mit optionalem Kinomodus und Doppelbett ausgestellt. Da die meisten Autos mehr als $90 \%$ der Zeit irgendwo geparkt sind und zukünftig mit großen Batterien in dieser Zeit auch energiemäßig autark sein können, mag mancher „Fahrer“ seinen Untersatz gern als Wohnzimmer nutzen.

Man kann auf dieser Basis unser etabliertes Modell von Mobilität komplett in Frage stellen. Zumindest zeigt dieser Ansatz aber, dass wir uns in einer sehr spannenden Phase des Wandels befinden und dass die großen Märkte in Asien und besonders China wichtige Impulse für die Zukunft setzen werden. Das Interieur der Zukunft braucht unser globales Denken, um das Leben an Bord für die Insassen sicher und angenehm zu gestalten. 